\title{
Preparation of ZnO Nanorods by Hydrothermal Process at Different Temperatures
}

\author{
R. K. Das \\ Dept. of Physics, Charuchandra College, University of Calcutta, Kolkata, India \\ *Corresponding Author: rkdas_171171@rediffmail.com \\ Available online at: www.isroset.org \\ Receive $12^{\text {th }}$ Sep 2017, Revised $20^{\text {th }}$ Sep 2017, Accepted $24^{\text {th }}$ Oct 2017, Online $30^{\text {th }}$ Oct 2017
}

\begin{abstract}
Here for the synthesis of $\mathrm{ZnO}$ (Zinc Oxide) nanorods we have used hydrothermal process. Seed layers were deposited on FTO (Fluorine doped tin oxide) glass substrates using electro deposition method with zinc nitrate dehydrate. ZnO nanorods were synthesized on annealed seeded layer by hydrothermal method using hexamethylenetetramine as a precipitant and zinc nitrate dehydrate as source at different temperatures $50^{\circ} \mathrm{C}, 65^{\circ} \mathrm{C}, 75^{\circ} \mathrm{C}$, and $85^{\circ} \mathrm{C}$. The crystal surfaces were investigated by Scanning Electron Microscopy (SEM). SEM produces image by using electrons rather than light photons. A beam of electrons is sent by electron gun which follows the vertical path and after travelling through the magnetic lens it hits the sample. After the beam hits the sample, electrons and X-rays are ejected and collected by detector to give final image. It is found that the dimension of $\mathrm{ZnO}$ nanorods changed with different temperature. SEM images show that the average diameters of $\mathrm{ZnO}$ nanorods are about $10-15 \mathrm{~nm}$ by changing growth temperature. The smallest diameter of $\mathrm{ZnO}$ nanorods is observed while the growth temperature is equal to $50{ }^{\circ} \mathrm{C}$. $\mathrm{ZnO}$ nanorods have applications in Quantum Dot Sensitized Solar Cells (QDSSC).
\end{abstract}

Keywords-Nanorods, Hydro thermal, SEM images, Nano struture, Zinc Oxide

\section{INTRODUCTION}

$\mathrm{ZnO}$ nanostructures have great importance in nanotechnology as nanotubes, nanowires, nanorods, nano belts, nanocables etc. $\mathrm{ZnO}$ is the material of the family of IIVI semiconductors. Binding energy of $\mathrm{ZnO}$ is $60 \mathrm{meV}$ and band gap energy is $3.37 \mathrm{eV}$ besides this it has high breakdown strength, cohesion and excitation stability for which it has greater importance in nanotechnology. For its vertical geometry this is suitable for filling with hole transporting materials [1-4]. There are various methods of preparing $\mathrm{ZnO}$ nanostructure such as vapour-liquid-solid growth, Template-based methods, chemical vapour deposition, and hydrothermal process [5-10]. Cobalt nanoparticles were prepared by modified Polyol process [11].

In this work, we have used the hydrothermal growth of $\mathrm{ZnO}$ nanorods on FTO substrates, and investigated them by scanning electron microscopy (SEM) at different temperatures. These $\mathrm{ZnO}$ nanorods are widely used to prepare QDSSCs. The hydrothermal method is used because of its advantages - it is a simple, can be performed at low temperature $\left(60-100{ }^{\circ} \mathrm{C}\right)$, has high efficiency and greater controllable process with respect to other methods performed which are highly power consuming and highly expensive [12-16].

Scanning Electron Microscope (SEM) creates an image when electron beam is focused over a surface. When the electrons in the beam interact with the sample that gives signals which gives information about the surface structure and composition. SEM analysis is nondestructive in the sense that the X-rays emitted during the interaction do not cause any volume loss of the sample. So the same material can be analyzed repeatedly. SEM is an instrument which produces image by using electrons rather than light photons. A beam of electrons is sent by electron gun and follows vertical path.Then the beam travels through the magnetic lens (this focus the beam down to the sample) and hits the sample. After that electrons and X-rays are ejected which are collected by detectors to give final image as shown in fig. 1 . In our knowledge the hydrothermal method used here is old technique but our experimental results obtained is purely different from the similar work done in past. In our future work we will study the optical and electrical properties of the prepared $\mathrm{ZnO}$ nanorod thin films.

This paper has been written into four distinct sectionsIntroduction, Experimental procedure, Results and discussion and conclusion. Introduction section gives the brief review of literature related to our present work. Experimental procedure contains the preparation of $\mathrm{ZnO}$ nanorods at different temperatures by hydrothermal method. Results and discussion section shows SEM images of $\mathrm{ZnO}$ nanoparticles at different temperatures and includes analysis and 
discussion of our results. Conclusion part gives the major conclusion drawn from our results.

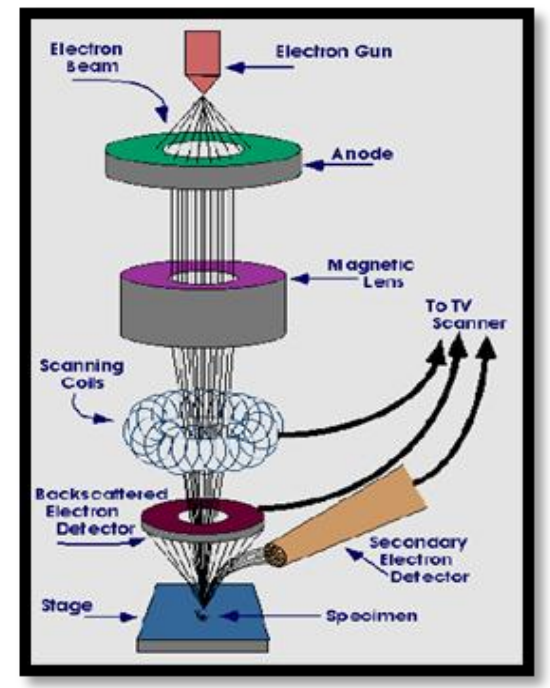

Fig1:Schematic diagram of SEM

\section{Experimental Procedure}

$\mathrm{ZnO}$ nanorods were grown on FTO substrates via a two-step process. In the first step, a thin seed layer was prepared on FTO substrates by using electrodeposition technology. In the second step, $\mathrm{ZnO}$ nano rods were grown on seed layer coated FTO substrates by hydrothermal technique. $0.074(2.5 \mathrm{mM})$ gram of zinc nitrate powder and 0.026 gram $(2.5 \mathrm{mM})$ of diethanolamine \& $100 \mathrm{ml}$ of de-ionized water were added to prepare the solution. This solution was stirred continuously for 2 hours at room temperature for obtaining clear homogenous solution. The stirred solution was taken in a beaker and the well cleaned FTO substrates were electrodeposited for five minutes at room temperature. Then these films were annealed in a furnace at a temperature of $200^{\circ} \mathrm{C}$ for 1 hour. The diagram shown in Figure. 2 shows the detailed preparation procedure of $\mathrm{ZnO}$ seed layers.

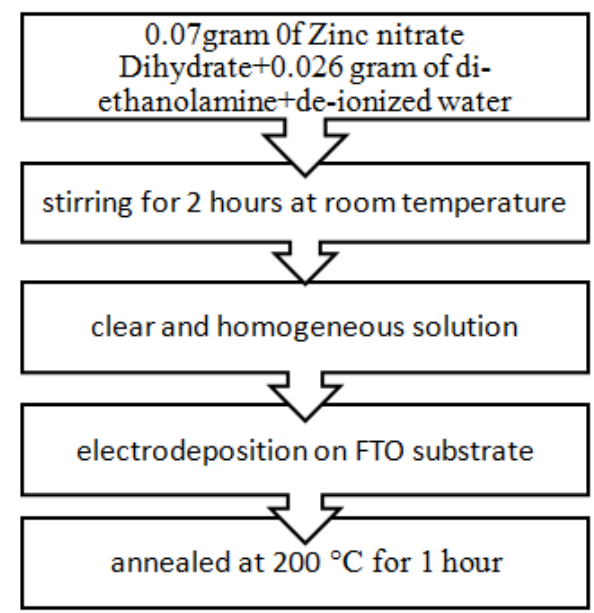

Figure 2: Flow chart showing the preparation of $\mathrm{ZnO}$ seed layer thin film
Hydrothermal method was used by suspending the $\mathrm{ZnO}$ seed coated FTO substrates. $\mathrm{ZnO}$ nanorods were grown using hydrothermal method by immersing a seeded FTO substrate in a glass beaker to containing $10 \mathrm{mM}$ of zinc nitrate and 20 $\mathrm{mM}$ of hexamethylenetetramine in a hot air oven and maintained at $90^{\circ} \mathrm{C}$ for 4 hours (HMTA) solution, which is the optimized ratio to grow $\mathrm{ZnO}$ nanorods. The solution was heated in a hot air oven and maintained at $90^{\circ} \mathrm{C}$ for 4 hours.

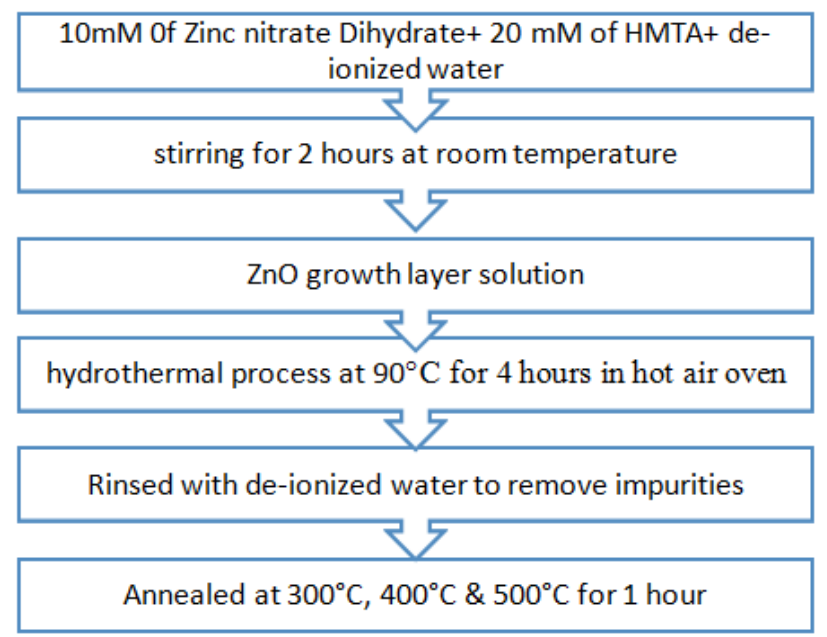

Fig3: Preparation of $\mathrm{ZnO}$ Nanorods

\section{RESULTS AND DISCUSSION}

SEM was used to investigate the nanostructure of $\mathrm{ZnO}$ nano needle. Below Figures show the SEM images of $\mathrm{ZnO}$ nanoneedle obtained under different growth temperatures. They show that a $\mathrm{ZnO}$ nanoneedles having a diameter of from $10-15 \mathrm{~nm}$ are formed under different growth temperatures at $50^{\circ} \mathrm{C}, 65^{\circ} \mathrm{C}, 75^{\circ} \mathrm{C}$ and $85^{\circ} \mathrm{C}$. So the dimensions of $\mathrm{ZnO}$ nanorods are changed with different temperature. The smallest diameter of $\mathrm{ZnO}$ nanorods is observed when the growth temperature is equal to $50{ }^{\circ} \mathrm{C}$. From Fig.4, the best growth temperature of $\mathrm{ZnO}$ nanorods is at $85^{\circ} \mathrm{C}$.

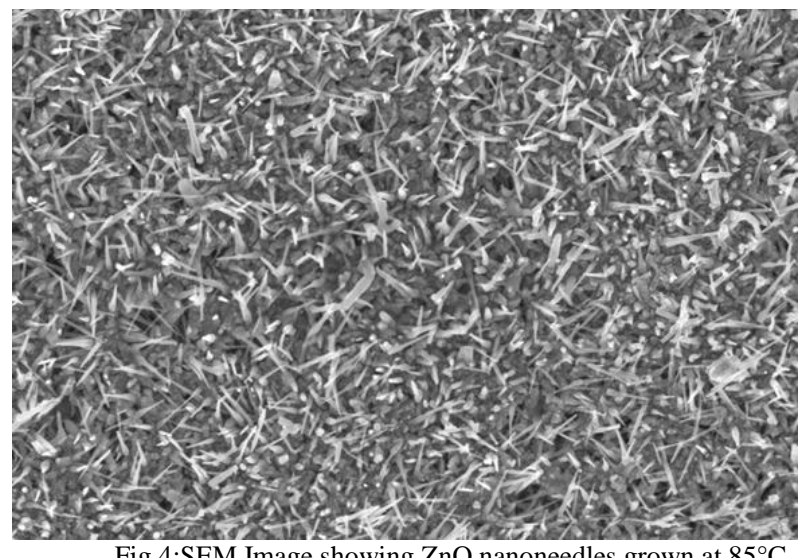

Fig.4:SEM Image showing $\mathrm{ZnO}$ nanoneedles grown at $85^{\circ} \mathrm{C}$ 


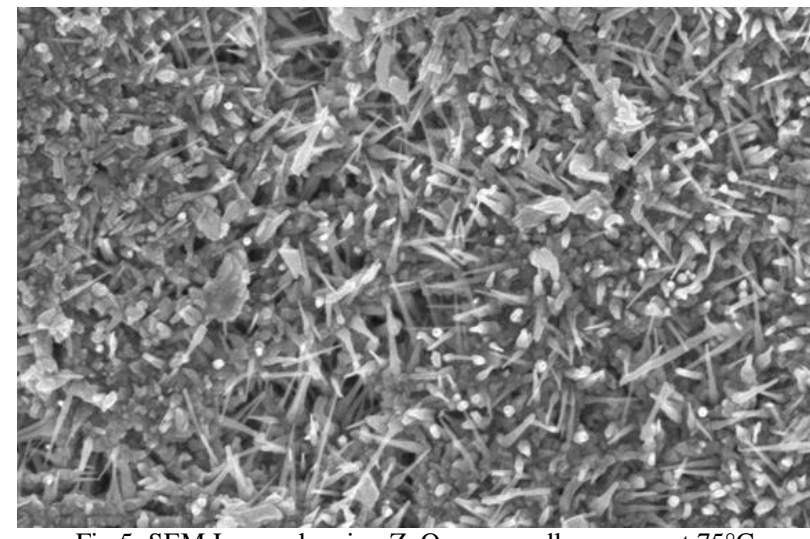

Fig.5: SEM Image showing $\mathrm{ZnO}$ nanoneedles grown at $75^{\circ} \mathrm{C}$

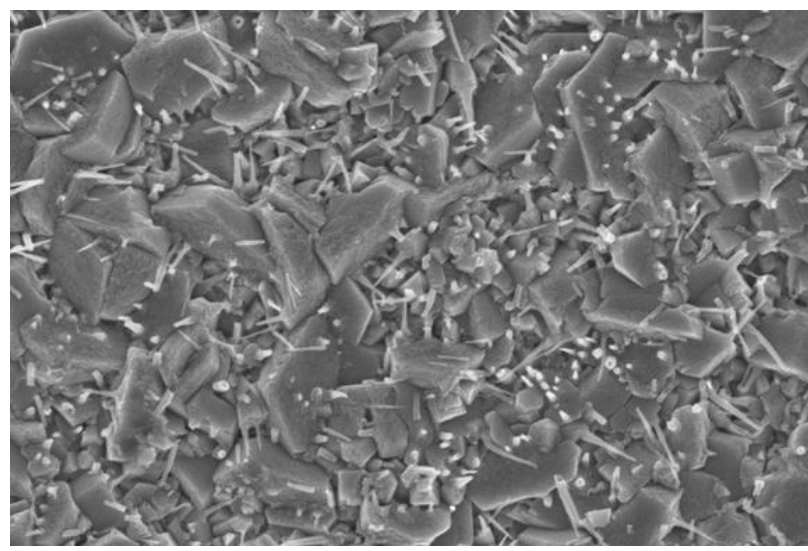

Fig.6: SEM Image showing $\mathrm{ZnO}$ nanoneedles grown at $65^{\circ} \mathrm{C}$

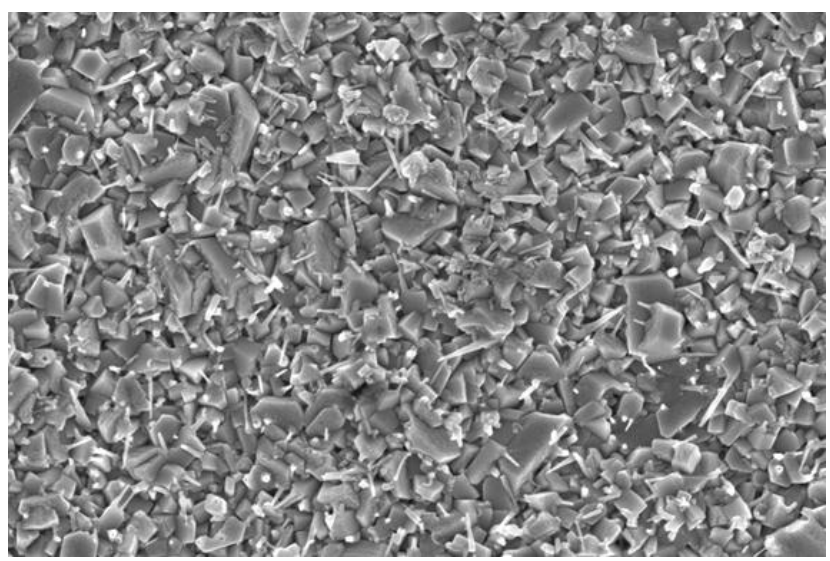

Fig.7: SEM Image showing $\mathrm{ZnO}$ nanoneedles grown at $50^{\circ} \mathrm{C}$

\section{CONCLUSION}

In summary, $\mathrm{ZnO}$ micro and nanostructure needles were synthesized by hydrothermal solution technique. $\mathrm{ZnO}$ rods grown at $85^{\circ} \mathrm{C}$ had a large aspect ratio than those obtained at $50{ }^{\circ} \mathrm{C}$. Our procedure allows the growth of $\mathrm{ZnO}$ nanorods with seeds layer. The controlled synthesis of $\mathrm{ZnO}$ nanorods opens new applications in the fabrication of nano devices in nanotechnology. The results presented in this report demonstrate that growth temperature, and deposition time have influence on the shape and ordering of $\mathrm{ZnO}$ nanoneedles. In our future work we will study optical and electrical properties of prepared $\mathrm{ZnO}$ nanorod thin films at different temperatures.

\section{Acknowledgment}

I am thankful to Department of Physics, Charuchandra College, University of Calcutta for giving me support.

\section{REFERENCES}

[1] W.U. Huynh, J.J. Dittmer, A.P. Alivisatos, "Investigation of Properties of $\mathrm{ZnO}$ Nanorad Structures by Chemical Vapor Deposition”, Science, vol.295, pp.2425-2427, 2002.

[2] T. Stubinger, W. Brutting, "Exciton diffusion andoptical interference in organic donor-acceptor photovoltaic cells", Journal of Applied Physics, vol.90, pp.3632-3641, 2001.

[3] C.J. Brabec, N.S. Sariciftci, J.C. Hummelen, "Origin of the Open Circuit Voltage of Plastic Solar Cells", Advanced Functional Materials, vol.11, pp.15-26, 2001.

[4] B. Pradhan, A. Bandyopadhyay, A. J Pal, "Tuning performance of donor-acceptor based self-assembled photovoltaic devices", Applied Physics Letters, vol.85, pp.633, 2004.

[5] M.H. Huang, Y. Wu, H. Feick, N. Tran, E.Weber, P.Yang, "Catalytic growth of zinc oxide nanowires by vapour transport", Advanced Materials, vol.13, pp.113-116, 2001.

[6] Y.C. Kong, D.P. Yu, B. Zhang,W. Fang, S.Q. Feng, "Ultravioletemitting $\mathrm{ZnO}$ nanowires synthesized by a physical vapor deposition approach,", Applied Physics Letters, vol.78, pp.407409, 2001

[7] J.-J. Wu, S.C. Liu, "Low-Temperature and Catalyst-Free Synthesis of Well-Aligned ZnO Nanorods on Si (100)", Advanced Matererials, vol.14, pp.215-218, 2002.

[8] J.-J. Wu, S.C. Liu, "Catalyst-Free Growth and Characterization of $\mathrm{ZnO}$ Nanorods", Journal of Physical Chemistry B, vol.106, pp.9546-9551, 2002.

[9] J. Zhang, L. Sun, H. Pan, C. Liao, C. Yan, "ZnO nanowires fabricated by a convenient route", New Journal of Chemistry, vol.26, pp.33-34, 2002.

[10] Y. Li, G.W. Meng, L.D. Zhang, F. Phillipp, "Ordered semiconductor $\mathrm{ZnO}$ nanowire. Arrays and their photoluminescence properties", Applied Physics Letters, vol.76, pp.2011-2014, 2000.

[11] G. Chandraprabha, T. Sankarappa, T. Sujatha, "Structure and magnetic studies of Cobalt Nanoparticles prepared by Modified Polyol Process", International Journal of Scientific Research in Physics and Applied Sciences, vol.5, Issue 4, pp. 17-20, 2017.

[12] C.X. Xu, A. Wei, X.W. Sun, Z.L. Dong, "Aligned ZnO nanorods synthesized by a simple hydrothermal reaction.",Journal of Physics D: Applied Physics, Vol. 39, pp. 1690-1693,2006

[13] J. Song, S. Baek, S. Lim," Effect of hydrothermal reaction conditions on the optical properties of ZnO nanorods", Physics B: Condensed Matter , vol.403 , pp.1960-1963, 2008.

[14] L. Vayssieres, K. Keis, S. Lindquist, A. Hagfeldt, "Hydrothermal Synthesis and Properties of Diluted Magnetic Semiconductor $Z n_{1}$. ${ }_{x} M n_{x} O$ Nanowires", Journal of Physical Chemistry B, vol.105, pp.3350-3352, 2001.

[15] B. Liu, C.H. Zeng, "Hydrothermal Synthesis of ZnO Nanorods in the Diameter Regime of $50 \mathrm{~nm}$ ", Journal of American Chemical Society, vol.125, pp. 4430-4431, 2003. 
[16] Z. Qiu, K.S. Wong, M. Wu, W. Lin, H. Xu, "Microcavity lasing behavior of oriented hexagonal $\mathrm{ZnO}$ nanowhiskers grown by hydrothermal oxidation ",Applied Physics Letters, vol. 84, pp. 2739-2741, 2004.

\section{Author Profile}

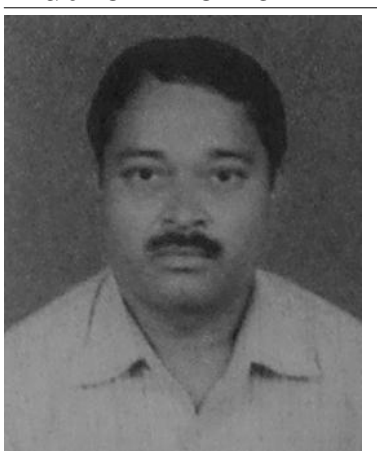

Mr. R.K. Das has completed B.Sc from St. Paul's Cathedral Mission College under university of Calcutta. He has completed M.Sc in physics from Calcutta University. He has been working (Lecturer and Assistant Professor Stage II) with Department of Physics, Charuchandra College, Kolkata which is affiliated to Calcutta University for 15 years. He has 6 research publications and 4 papers have been communicated till now. And his research topic is basically electronics. He has taught Physics for 15 years and basically the topics are Electronics, Quantum Mechanics, Classical Mechanics, Electrodynamics, Magnetism, Thermodynamics, Electromagnetic Theory, Solid State Physics, Relativity. Presently he is continuing in his teacher job. 